\title{
Myriad manifestations of myxoma
}

\author{
S. Ram Kumar, MD, PhD, FACS
}

\footnotetext{
From the Division of Cardiac Surgery, Department of Surgery, Keck School of Medicine of University of Southern California; and the Heart Institute, Children's Hospital of Los Angeles, Los Angeles, Calif.

Disclosures: Author has nothing to disclose with regard to commercial support.

Received for publication June 22, 2017; accepted for publication July 17, 2017; available ahead of print Aug 10 , 2017.

Address for reprints: S. Ram Kumar, MD, PhD, FACS, Children's Hospital, Los Angeles, 4650 Sunset Blvd, Mailstop \#66, Los Angeles, CA 90027 (E-mail: rsubramanyan@chla.usc.edu).

J Thorac Cardiovasc Surg 2017;154:1383-4

$0022-5223 / \$ 36.00$

Copyright (c) 2017 by The American Association for Thoracic Surgery

http://dx.doi.org/10.1016/j.jtcvs.2017.07.017
}

Myxomas are the most common form of benign primary cardiac tumor. The vast majority is found in the left atrium (Figure 1), usually attached to the atrial septum by a stalk. Significantly fewer myxomas are found in the right atrium or ventricles. Histologically, myxomas are made up of stellate mesenchymal cells in a myxoid stroma. Since the first description of their successful resection in the 1950s, left atrial myxomas have been considered highly curable, with excellent outcomes in the long term. To ensure complete removal of the tumor, the stalk is usually resected with a portion of tumor-free atrial septum, followed by primary or patch reconstruction of the septum. Tumor recurrence is uncommon, although not unknown, ${ }^{1}$ after complete excision.

Early diagnosis of an atrial myxoma continues to be challenging largely because the symptomatology can be subtle and often vague. Because these tumors are pedunculated, soft, and often friable, embolization of some or the entire tumor has been described, with symptoms related to the size and site of embolus. Infrequently, nonspecific systemic symptoms, such as joint pain and low-grade fevers, can be present, and in areas where rheumatic fever is still prevalent, these symptoms and the ensuing mitral valve pathology can often lead to the misdiagnosis of rheumatic heart disease. Interesting presentations, such as tumor "plop" heard in diastole during routine auscultation or angina resulting from coronary steal by a highly vascularized tumor, ${ }^{2}$ have all been reported.

Most frequently, left atrial myxomas cause mitral valve symptoms. Mitral valve stenosis is the more common and intuitively understandable abnormality, when a sufficiently large tumor physically obstructs blood flow into the mitral valve. A smaller tumor can prolapse into the open valve, thereby reducing its effective orifice, also resulting in mitral stenosis. Tumor excision thus effectively relieves mitral stenosis. Not infrequently, mitral regurgitation can be seen in the setting of a left atrial myxoma. Although the exact etiology is not known, several potential mechanisms have been suggested. The tumor, because of either its location or size, may impede valve coaptation and closure. When a tumor prolapses into the ventricular cavity, it can
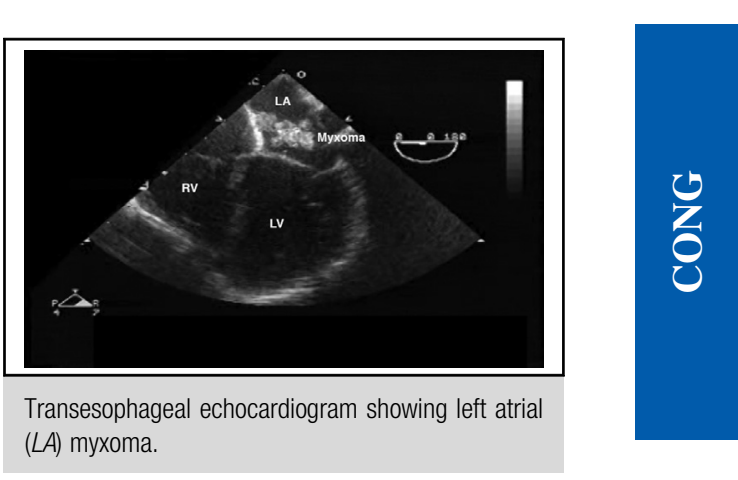

Central Message

Left atrial myxomas can affect mitral valve function in myriad ways. Tailoring surgical approach to the pathophysiology is required for superior long-term outcomes.

See Article page 1381.

disrupt the chordal mechanisms, thereby affecting valve function through a prolonged period. More interestingly, preoperative imaging studies have shown that the mitral annulus may be enlarged in some patients with myxoma. This may result either from mechanical stretching of the valve and annulus by tumor protrusion or as a compensatory change to increase effective valve orifice to accommodate blood flow across the mitral valve obstructed by the tumor. In this issue of the Journal, Blanco and colleagues ${ }^{4}$ elegantly report another interesting mechanism of mitral regurgitation. The tumor was "knocking on the mitral valve" during every heartbeat, causing a perforation in the posterior mitral leaflet. A similar "wrecking ball effect"

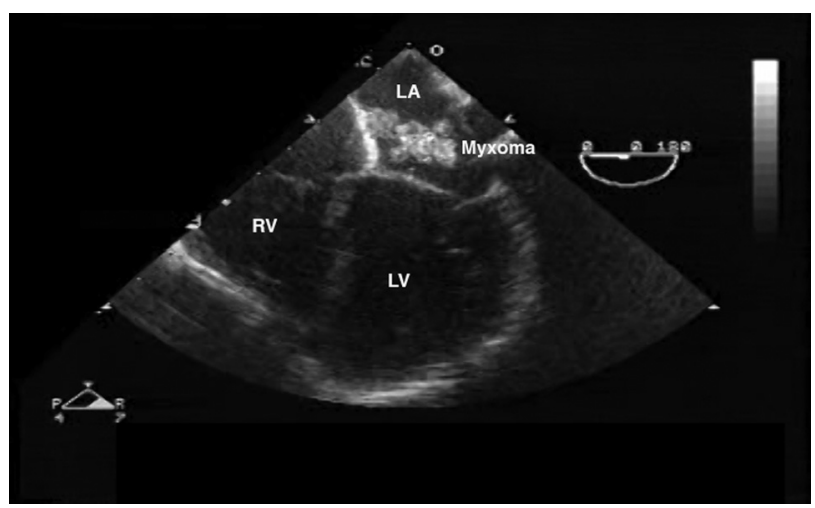

FIGURE 1. Transesophageal echocardiogram showing left atrial myxoma in the usual position. $L A$, Left atrium; $R V$, right ventricle; $L V$, left ventricle. (Echocardiogram courtesy of Pierre Wong, MD, Pediatric Cardiologist, Children's Hospital, Los Angeles, Calif.) 
has been described from a right atrial myxoma. ${ }^{5}$ In this report, Blanco and colleagues ${ }^{4}$ repaired the defect in the posterior leaflet and also performed an annuloplasty to limit postoperative mitral regurgitation, reiterating the role of annular dilation in this disease process. Reports such as these reinforce the need to tailor surgical approaches to the individual patient's disease process, rather than taking a generic approach on the basis of the diagnosis. Understanding the pathophysiology in the individual patient will allow us to address the disease process effectively and ensure superior long-term outcomes.

\section{References}

1. Sadeghi N, Sadeghi S, Karimi A. Mitral valve recurrence of a left atrial myxoma. Eur J Cardiothorac Surg. 2002;21:568-73.

2. Stiver K, Bittenbender P, Whitson BA, Bush CA. Left Atrial Myxoma Causing Coronary Steal: An Atypical Cause of Angina. Tex Heart Inst J. 2015; 42:270-2.

3. Chen J, Yang ZG, Ma ES, Zhang Q, Liu X, Guo YK. Preoperative assessment of mitral valve abnormalities in left atrial myxoma patients using cardiac CT. Oncotarget. March 11, 2017 [Epub ahead of print].

4. Blanco M, Laguna G, Carrascal Y. Myxoma knocking on the mitral door: a singular mechanism of mitral regurgitation. J Thorac Cardiovasc Surg. 2017; 154:1381-2.

5. Nardi C, De Carlo M, Milano A, Bortolloti U. The wrecking ball effect of a right atrial myxoma. Eur J Cardiothorac Surg. 2000;17:338. 